\title{
Presentation of chronic myeloid leukemia as promyelositic blastic transformation: A case report and literature review
}

\author{
Azar Abiyev"*, Orhan Zengin ${ }^{2}$, Mustafa Erkut Onder ${ }^{2}$ and Sibel Arslan ${ }^{3}$ \\ ${ }^{1}$ Department of Internal Medicine, Faculty of Medicine, Gaziantep University, Gaziantep, TR-27310, Turkey \\ ${ }^{2}$ Department of Rheumatology, Faculty of Medicine, Gaziantep University, Gaziantep, TR-27310, Turkey \\ ${ }^{3}$ Department of Pathology, Faculty of Medicine, Gaziantep University, Gaziantep, TR-27310, Turkey
}

\begin{abstract}
Chronic myelocytic leukemia (CML) is a clonal disorder involving the pluripotent stem cell and is consistently associated with the BCR-ABL1 fusion gene located on the Philadelphia chromosome. The disease typically evolves in 3 distinct clinical stages: chronic and accelerated phases and blast crisis. The promyelocytic blast crisis is a rare form of transformation during the evolution of CML. Here we report a case of promyelocytic blastic crisis with $t(15 ; 17)$ in addition to $t(9 ; 22)$.
\end{abstract}

\begin{abstract}
Abbreviations: BMA: Bone Marrow Aspiration; BMB: Bone Marrow Biopsy

\section{Introduction}

Chronic myelocytic leukemia (CML) is a clonal disorder of pluripotent stem cell. It is characterized by the dysregulated production and uncontrolled proliferation of mature and maturing granulocytes with fairly normal differentiation. Philadelphia chromosome occurs in 95\% of CML cases. CML is associated with the fusion of two genes: BCR (on chromosome 22) and ABL1 (on chromosome 9) resulting in the BCR-ABL1 fusion gene [1]. Acute promyelocytic leukemia (APL) is a biologically and clinically different type of acute myeloid leukemia (AML). It occurs result of reciprocal translocation of PMLRARA fusion gene on chromosome 15 and 17 and positive $90 \%$ of AML patients. In CML progression toblastic transformation develops block of differentiation and apoptosis CML stem cells or progenitor cells. Genetic instability and epigenetics modifications of BCR-ABL is probably responsible for this pathogenesis and acute leukemic transformation [2]. The promyelocytic blast crisis is a rare form of transformation during the evolution of CML. The morphology and immunophenotype of the blasts were similar to those seen in acute promyelocytic leukemia APL (3). Here we report a case of promyelocytic blastic crisis with $\mathrm{t}(15 ; 17)$ in addition to $\mathrm{t}(9 ; 22)$.
\end{abstract}

\section{Case report}

A 19-year old man applied the hematology department with complaints of abdominal pain, fatigue, nausea, vomiting and epistaxis for one month. He had found out through the medical history that he was diagnosed with CML 6 months ago and Imatinib mesylate equivalent to $400 \mathrm{mg}$ /day was appointed (Figure 1a). An irregular intake of Imatinib mesylate was also found out. A physical examination showed that the spleen had crossed costal margin $12 \mathrm{~cm}$ and no hepatomegaly. Complete blood count was also found out that the hemoglobin level was $7.4 \mathrm{gr} / \mathrm{dl}(13.5-17.5 \mathrm{gr} / \mathrm{dl})$, platelet count was $16.000 / \mathrm{mcl}(150.000-450.000 / \mathrm{mcl})$ and WBC count was $3.3 \times$ $10^{9} / \mathrm{L}\left(3.5-10.5 \times 10^{9} / \mathrm{L}\right)$. The patient had no evidence of coagulopathy with clinical and laboratory findings of disseminated intravascular coagulation (DIC). Promyelocytic blast with Auer rod were observed in the proportion of $70 \%$ to hypercellularity after the bone marrow aspiration and biopsy examination (Figure $1 \mathrm{~b}-\mathrm{d}$ ). Flow cytometric analysis revealed that more than $20 \%$ of blastic cells were immunepositive for CD45, CD13, CD33, CD117, MPO and immune-negative for CD34, HLA-DR expression. Translocation of $\mathrm{t}(9 ; 22)$ (BCR-ABL) and $\mathrm{t}(15 ; 17)$ were positive.

A diagnosis of chronic myelocytic leukemia with promyelocytic blastic transformation was made. Remission induction chemotherapy was initiated with ATRA $45 \mathrm{mg} / \mathrm{m} 2$, cytosine arabinoside $(200 \mathrm{mg} /$ $\mathrm{m}^{2} /$ day), idarubicin $\left(12 \mathrm{mg} / \mathrm{m}^{2} /\right.$ day $)$ and dasatinib $140 \mathrm{mg} /$ day. After induction chemotherapy a bone marrow biopsy and aspiration being repeated after a month. Normocellular bone marrow and aspiration was seen (Figure 2$)$. $\mathrm{T}(15 ; 17)$ translocation was resulted positively in the proportion of 0.0004 . $\mathrm{T}(9 ; 22)(\mathrm{BCR}-\mathrm{ABL})$ area was seen positive in the proportion of 0.004 and $t(15 ; 17)$ was negative in the analysis of blood sample taken through RT-PCR method from a bone marrow after chemotherapy. The second cure consolidation chemotherapy was commenced for the patient with dasatinib $140 \mathrm{mg}$ in a day. There were negativity of $t(15 ; 17)$ and, $t(9 ; 22)$. Allogeneic bone marrow transplantation was planned in the case and follow-up as well as treatment is being continued.

\section{Discussion}

The promyelocytic blastic crisis is an uncommon type of CML blastic transformation. We report a case of promyelocytic blastic crisis with $t(15 ; 17)$ in addition to $t(9 ; 22)$. The morphology and immunophenotype

Correspondence to: Azar Abiyev, Department of Internal Medicine, Faculty of Medicine, Gaziantep University, Gaziantep, TR-27310, Turkey, Tel: +90 342360 60 60; Fax: +90 34236100 63; E-mail: dr_abiyev@yahoo.com

Key words: chronic myelocytic leukemia, acute promyelocytic leukemia, Philadelphia chromosome

Received: August 08, 2017; Accepted: August 27, 2017; Published: August 30, 2017 


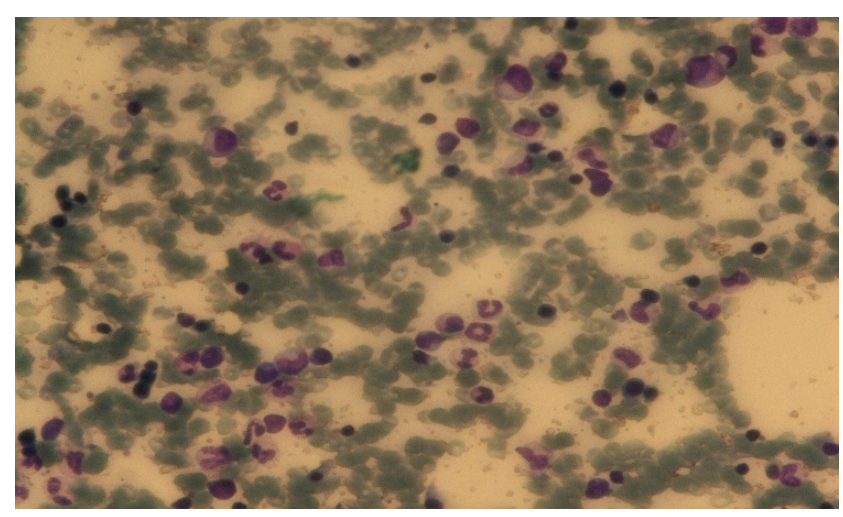

Figure1a. BMA, CML, Giemsa stain X 100.

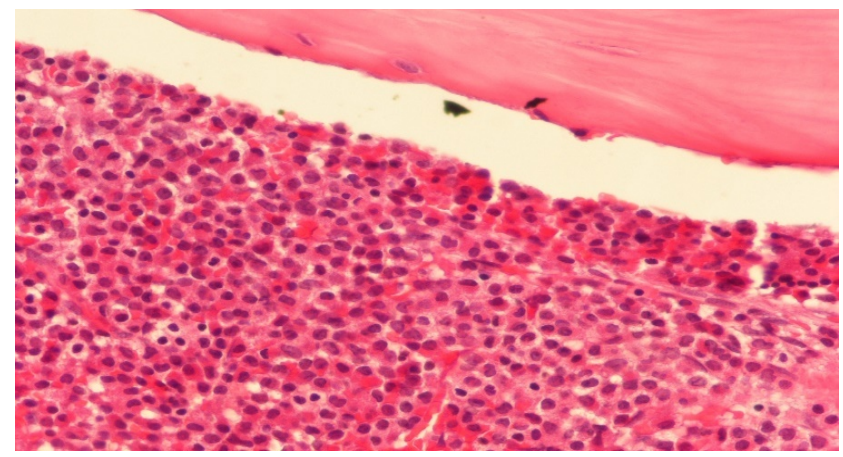

Figure 1b. BMB, AML, immunohistochemical stain $\mathrm{x} 400$

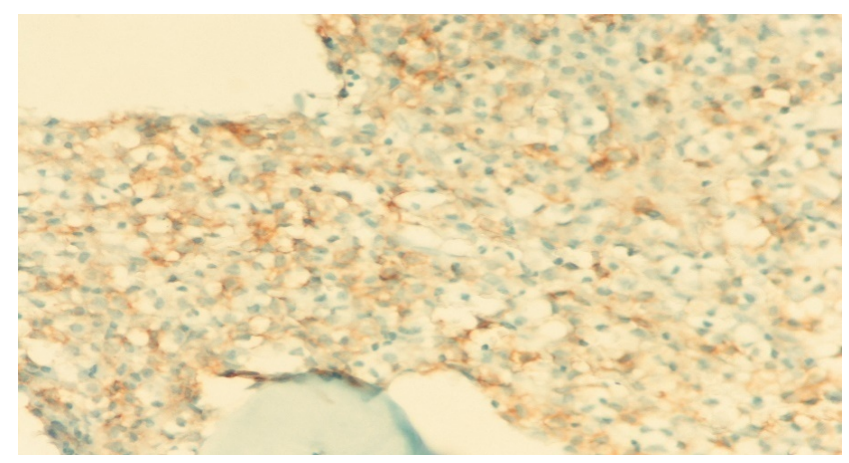

Figure 1c. BMB, AML, CD117 positivitiy, immunohistochemical stain $\mathrm{x} 400$

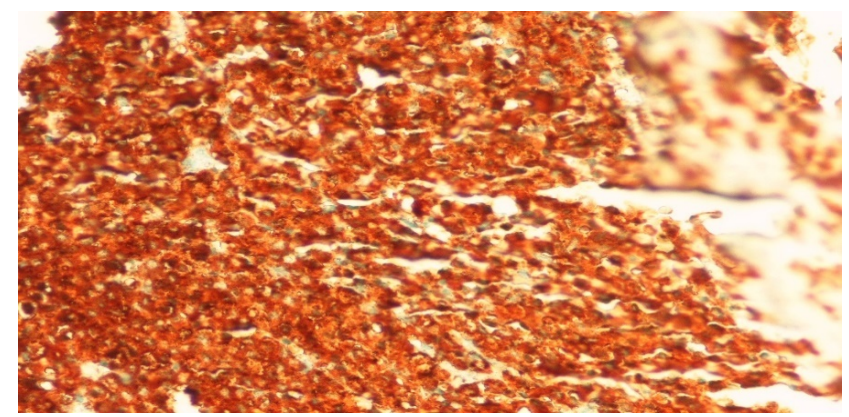

Figure 1d. BMB, AML, MPO positivitiy, immunohistochemical stain $\mathrm{x} 400$

of the blasts were similar which are seen in acute promyeloctic leukemia. The $t(15 ; 17)$ and $t(9 ; 22)$ were confirmed by RT-PCR. The patient had no evidence of coagulopathy with clinical and laboratory findings of DIC. The duration of chronic phase to promyelocytic blastic crisis was about one year in our patient. But blastic transformation in
CML develops in ranges to 8 months to 9 years normally [4]. Blastic transformation was diagnosed with one year in our patient. We found no chromosomal aberrations and translocations. Genomic instability and less vulnerability of CML stem cell to imatinib may cause to CML progression in a little time. Although imatinib mesylate was used by the patient whom BCR-ABL suppressed or undergo apoptosis while leukemic cells developed to clonal evaluation [5].

Promyelocytic blastic crisis of CML is highly rare, accounting for about 30 cases searching English literature before 2007 [5]. The first case with promyelocytic blastic crisis during Imatinib mesylate therapy was published by Gozetti et al. [6] who is 50 years old male patient.

In the early stages of CML chronic phase a clonal evolution developed by the adding of PML/RARA translocation may result with this clinic illustration. Some novel translocations and chromosomal aberrations, like $\mathrm{t}(5 ; 13)(\mathrm{q} 12 ; \mathrm{p} 13)$ and $\mathrm{t}(15 ; 20)(\mathrm{q} 22 ; \mathrm{p} 13), 17 \mathrm{q},+8$, del $(7 \mathrm{q})$ may occur during promyelocytic crisis of CML [7]. But, De Botton et al. [8] showed no significant difference in complete remission, event-free survival, relaps or overall survival at 2 years between the prognosis of APL with additional chromosomal changes and $t(15 ; 17)$ in 292 patients who are treated with ATRA and chemotherapy. The most commonly seen chromosomal abnormalities were trisomy 8 , deletions and translocations chromosomes 9, 7, 21 and 17 [8]. Rosenthal et al. [9] in a series of 89 cases of blast crisis of CML found two cases classified as APL. The two of CML revealed $t(15 ; 17)$ in addition to $t(9 ; 22)$. Both patients developed disseminated intravascular coagulation at presentation or during treatment of blastic crisis. Oku et al. [10] reported a 66-year-old woman with promyelocytic crisis of CML diagnosed by demonstration of both BCR/ABL and PML/RAR alpha chimeric genes in leukemic cells by karyotype and fluorescence in situ hybridization analysis. Authors claimed that clonal evolution with addition of the PML/ RAR alpha translocation may have arisen in the early chronic phase of CML, with expansion of this clone during imatinib treatment [10]. Yamamoto and his friends reported a CML case transformed into APL with T315I mutation in only one CML patient who used dasatinib. In this case combination therapy with imatinib and arsenic trioxide achieves favorable outcomes for promyelocytic blastic crisis finally with allogeneic stem cell transplantation [11].

Additional chromosomal abnormalities had higher rates of coagulopathy, thrombocytopenia and higher relapse rate compared to $t(15 ; 17)$ alone [12]. But, our patients had no findings of coagulopathy which may have relation with no chromosomal abnormalities and achieved complete cytogenetic remission after second chemotherapy cycle with dasatinib. This is the first case who was achieved complete remission with using dasatinib during promyelocytic blastic crisis. It is possible to assume that dasatinib contributed to achieve complete remission in this case with negativity of $t(9 ; 22)$ after treatment. Transformation of CML to APL is a rare clinical setting appropriate treatment approach has yet to be determined.

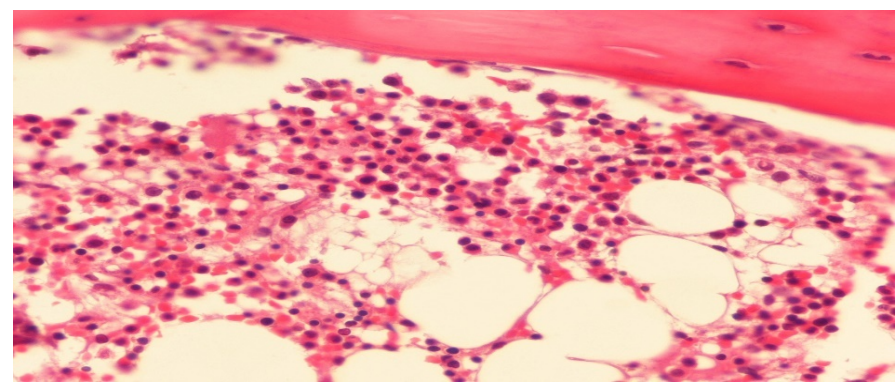

Figure 2. BMB, Normocellular bone marrow, immunohistochemical stain x 400 . 


\section{References}

1. Calabretta B, Perrotti D (2004) The biology of CML blast crisis. Blood 103: 4010-4022. [Crossref]

2. Emilia G, Sacchi S, Selleri L, Zucchini P, Artusi T, et al. (1987) Promyelocytic crisis of chronic myeloid leukaemia. Br J Haematol 66: 276-277. [Crossref]

3. Hogge DE, Misawa S, Schiffer CA, Testa JR (1984) Promyelocytic blast crisis in chronic granulocytic leukemia with 15;17 translocations. Leuk Res 8: 1019-1023. [Crossref]

4. Chung HJ, Chi HS, Cho YU, Park CJ, Seo EJ, et al. (2008) Promyelocytic Blast Crisis of Chronic Myeloid Leukemia during Imatinib Treatment. Ann Clin Lab Sci 38: 283286. [Crossref]

5. Gozzetti A, Bocchia M, Calabrese S, Pirrotta MT, Crupi R, et al. (2007) Promyelocytic blast crisis of chronic myelogenous leukemia during imatinib treatment. Acta Haematol 117: 236-237.

6. Shah B, Gajendra S, Gupta R, Sharma A (2015) Novel Cytogenetic Aberrations in Patient of Chronic Myeloid Leukemia with Blast Crisis. J Clin Diagn Res 9: XD05XD06. [Crossref]
7. De Botton S, Chevret S, Sanz M, Dombret H, Thomas X, et al. 2000) Additional chromosomal abnormalities in patients with acute promyelocyticleukaemia (APL) do not confer poor prognosis: results of the APL 93 trial. B r J Haematol 111: 801-806. [Crossref]

8. Rosenthal NS, Knapp D, Farhi DC (1995) Promyelocytic blast crisis of chronic myelogenous leukemia. A rare subtype associated with disseminated intravascular coagulation. Am J ClinPathol 103: 185-188. [Crossref]

9. Oku E, Imamura R, Nagata S, Takata Y, Seki R, et al. (2007) Promyelocytic crisis of chronic myelogenous leukaemia during imatinibmesylate treatment. Acta Haematol 117: 191-196. [Crossref]

10. Yamamoto E, Yamazaki E, Ishiyama Y, Koyama S, Ishii Y, et al. (2014) T315I positive promyelocytic crisis of chronic myeloid leukemia. Rinsho Ketsueki 55: 692-696. [Crossref]

11. Cervera J, Montesinos P, Hernández-Rivas JM, Calasanz MJ, Aventín A, et al. (2010) Additional chromosomal abnormalities in patients with acute promyelocytic leukemia treated with all-trans retinoic acid and chemotherapy. Haematologica 95: 424-431. [Crossref]

Copyright: (C2017 Abiyev A. This is an open-access article distributed under the terms of the Creative Commons Attribution License, which permits unrestricted use, distribution, and reproduction in any medium, provided the original author and source are credited. 